\title{
Terminação de machos e fêmeas de corte suplementados em campo nativo e pastagem cultivada para abate aos 18 meses de idade
}

\author{
Finishing beef steers and heifers slaughtered at 18 months \\ of age on native and cultivate pasture with supplement
}

\author{
Carlos Santos Gottschall', Leonardo Canali Canellas ${ }^{2}$, Eduardo Tonet Ferreira ${ }^{3}$ \& Hélio Radke Bittencourt ${ }^{4}$
}

\section{RESUMO}

O abate precoce de bovinos de corte visa elevar a produtividade do rebanho, encurtando o ciclo de produção, permitindo um giro rápido do capital investido. A suplementação alimentar de novilhos em pastejo acelera o crescimento dos animais permitindo a redução da idade de abate dos mesmos. O trabalho objetivou analisar o desempenho bio-econômico de bovinos de corte submetidos à suplementação alimentar para abate aos 18 meses de idade. Foram utilizados 47 novilhos (as) de corte, sendo 21 machos (grupo 18M) e 26 fêmeas (grupo 18F) com peso médio inicial de 282,62 e 278,19 kg (p>0,05), respectivamente. Entre 27/5 e 21/7/2005 os dois grupos foram submetidos à suplementação em campo nativo, com concentrado na base de $0,6 \%$ do peso vivo ( $1^{\circ}$ Período). Em 22/7, os animais foram transferidos para pastagem de azevém recebendo concentrado na base de $0,8 \%$ do peso vivo até o abate do último lote, em $26 / 10$ ( $2^{\circ}$ Período). A análise estatística consistiu da utilização do teste $t$ de Student para a comparação entre os dois grupos. Machos, em relação a fêmeas, obtiveram maior $(\mathrm{p}<0,01)$ ganho de peso médio diário no $1^{\circ}$ Período (0,550 vs 0,320 kg/dia), peso médio ao final do $1^{\circ}$ Período (312,86 vs $\left.295,77 \mathrm{~kg}\right)$, ganho de peso médio diário no $2^{\circ}$ Período (1,302 vs 1,022 kg/dia), ganho de peso médio diário no período total $(0,979$ vs $0,724 \mathrm{~kg} / \mathrm{dia})$, peso médio ao abate $(411,48$ vs $371,9 \mathrm{~kg})$ e porcentagem de ganho de peso $(45,94$ vs 34,01\%). Machos também obtiveram maior ( $\mathrm{p}<0,01)$ margem bruta/animal ( $\mathrm{R} \$ 118,95$ vs $\mathrm{R} \$ 39,82)$, lucratividade no período (20,63 vs 7,52\%) e lucratividade/mês $(4,79$ vs $1,88 \%)$. O ganho de peso médio diário no $2^{\circ}$ Período foi maior $(\mathrm{p}<0,01)$ em relação ao ganho de peso médio diário no $1^{\circ}$ Período para os dois grupos. A maior eficiência biológica dos machos permitiu um maior retorno econômico em relação às fêmeas. O processo terminação através de suplementação alimentar em pastejo mostrou-se viável economicamente.

Descritores: novilhos (as) de corte, suplementação, terminação intensiva, desempenho biológico, análise econômica.

\section{ABSTRACT}

The slaughtered of early beef cattle focus on to increase the profit from the herd, which makes the cycle of production shorter, allowing a faster refund of the invested money. The feeding using supplement on pasture gives the opportunity to steers to accelerate their growth in order to slaughter them earlier. The aim of this study was to analyse the bioeconomic performance of beef cattle submitted of supplementary feeding, slaughtered at 18 months old. Fourty-seven beef steers/heifers were separated in two groups according to the sex: 21 steers (18M group) and 26 heifers (18F group) with 282.62 and $278.19 \mathrm{~kg}$ ( $\mathrm{p}>0.05)$ at the beginning of the experiment respectively. Between 05-27-2005 and 07-21-2005 the steers/heifers were submitted to the supplementary feeding on native pasture, receiving a concentrate with an amount of 0.6\% of your live weight ( $1^{\text {st }}$ Period). In 07-22-2005 the steers/heifers were transferred to the Lolium multiflorum pasture, receiving $0.8 \%$ of your live weight in concentrate until the slaughtered ( $2^{\text {nd }}$ Period). The statistic analysis consisted of the utilization of test $t$ of Student. Steers obtained greater ( $<<0.01$ ) average daily gain on the $1^{\text {st }}$ period $(0.550 v s 0.320 \mathrm{~kg} /$ day $)$, weight at the end of the $1^{\text {st }}$ period $(312.86 v s 295.77 \mathrm{~kg})$, average daily gain on the $2^{\text {nd }}$ period (1.302 vs $1.022 \mathrm{~kg} /$ day), average daily gain on the whole period ( $0.979 v s 0.724 \mathrm{~kg} /$ day), weight at slaughtered (411.48 vs $371.9 \mathrm{~kg}$ ) e \% of weight gain (45.94 vs 34.01\%). Steers achieved a higher gross profit (R\$118.95 vs $\mathrm{R} \$$ 39.82), it was more lucrative on the period (20.63 vs 7.52\%) and on the month (4.79 vs 1.88\%). The higher biological efficiency allowed the steers to get a better economic efficiency. The supplement on pasture was economically viable in the finished process.

Key words: beef steers/heifers, supplementary feed, intensive finishing, biological performance, economic analysis. 


\section{INTRODUÇÃO}

No Rio Grande do Sul, as pastagens nativas são responsáveis por cerca de $90 \%$ da forragem utilizada pelo rebanho bovino do Estado [2]. Essas pastagens apresentam maior produção e qualidade de forragem durante o período primavera-verão e baixa produção e qualidade de forragem no outono-inverno $[16,23]$. Com isso, o sistema produtivo baseado exclusivamente a campo é frágil e sujeito a uma sazonalidade produtiva muito intensa [10,12], resultando em baixa eficiência reprodutiva e em abates tardios [4,35]. Portanto, a adoção de medidas que elevem a produtividade encurtando o ciclo de produção tornam-se fundamentais para tornar a atividade rentável [30].

Nesse contexto, a suplementação alimentar em campo nativo no período outono-inverno, pode ser utilizada para diminuir as perdas decorrentes da baixa disponibilidade de nutrientes apresentada pelas pastagens naturais nesse período, permitindo assim o abate precoce dos animais $[3,29,34]$. A utilização de pastagens de gramíneas anuais (azevém e aveia) também pode ser uma alternativa para suprir o déficit alimentar na estação fria $[5,15,21,32]$. Além disso, a suplementação com alimentos concentrados pode ser inserida para otimizar a utilização de pastagens hibernais, aumentando o desempenho individual dos animais e/ou a produção animal por unidade de área [19,25,36].

Contudo, a opção pelo uso da suplementação deve basear-se numa análise de rentabilidade, e essa, por sua vez, será dependente das restrições econômicas de cada propriedade rural [31]. O objetivo do presente trabalho foi analisar o desempenho de machos e fêmeas de corte, suplementados em campo nativo e pastagem cultivada de inverno, abatidos aos 18 meses de idade.

\section{MATERIAIS E MÉTODOS}

O trabalho foi realizado em uma propriedade particular situada no município de Glorinha, Rio Grande do Sul, entre 27/5 e 26/10/2005. Quarenta e sete novilhos (as) de corte cruzas Angus, Hereford e Nelore foram submetidos a dois períodos de suplementação alimentar para abate aos 18 meses. Os animais foram divididos em dois grupos, sendo 21 machos castrados, compondo o grupo $18 \mathrm{M}$, e 26 fêmeas vazias, compondo o grupo $18 \mathrm{~F}$.

Os animais identificados individualmente foram pesados no início do processo e por ocasião das ven- das. Além disso, ocorreram pesagens a cada 20 dias em média, para avaliação do desempenho dos animais e eventuais ajustes na dieta. Anteriormente às pesagens, os novilhos (as) foram submetidos a um jejum total de 14 horas. Os animais foram abatidos de forma escalonada conforme o grau de acabamento desejado, expresso por visualização de gordura subcutânea, não havendo exigência de peso mínimo de carcaça.

Durante os 12 primeiros dias, os animais foram submetidos a uma adaptação ao alimento concentrado, sendo esse introduzido gradualmente à dieta. Entre 27/5 e 21/7/2005 os dois grupos foram suplementados em campo nativo $(\mathrm{CN})$, com lotação média de $300 \mathrm{~kg}$ de peso vivo/ha, recebendo no cocho um concentrado na base de $0,6 \%$ do peso vivo, correspondendo ao $1^{\circ}$ período $\left(1^{\circ} \mathrm{P}\right)$. Em $21 / 7$, os dois grupos foram transferidos para pastagem de azevém (Lolium multiflorum), proveniente de ressemeadura natural em resteva de lavoura de soja, sob lotação média de $800 \mathrm{~kg}$ de peso vivo/ha, sendo suplementados até o abate com concentrado na base de $0,8 \%$ do peso vivo, correspondendo ao $2^{\circ}$ período $\left(2^{\circ} \mathrm{P}\right)$. A cada 20 dias, em média, ocorriam ajustes na quantidade de concentrado fornecida, a fim de manter os respectivos níveis de fornecimento para cada período.

A dieta foi ajustada conforme [22] para GMD de $0,6 \mathrm{~kg} / \mathrm{dia}$ no $1^{\circ} \mathrm{P}$ e de $1,0 \mathrm{~kg} / \mathrm{dia}$ no $2^{\circ} \mathrm{P}$. O concentrado utilizado foi produzido na propriedade, e era composto por grãos de soja e milho moídos, farelo de trigo e calcário calcítico. No $1^{\circ} \mathrm{P}$, o concentrado continha valores estimados de $18 \%$ de proteína bruta (PB) e $75 \%$ de nutrientes digestíveis totais (NDT). No $2^{\circ} \mathrm{P}$ esses valores eram, respectivamente de $15 \%$ e $75 \%$. Os dois grupos foram submetidos ao pastejo contínuo, manejados em piquetes com cerca elétrica separando machos de fêmeas. A oferta inicial de forragem foi estimada visualmente a fim de proporcionar as mesmas condições alimentares para os dois grupos. O concentrado era fornecido uma vez ao dia, às 17 horas, em cochos com espaço linear mínimo de $50 \mathrm{~cm}$ por animal. Os animais tiveram livre acesso, durante todo o período, a uma mistura mineral contendo $63 \mathrm{~g}$ de fósforo por $\mathrm{kg}$ de produto. Durante o $2^{\circ} \mathrm{P}$, a pastagem de azevém recebeu uma cobertura de nitrogênio (uréia) de $100 \mathrm{~kg} / \mathrm{ha}$. O controle sanitário seguiu o calendário normal da propriedade, visando principalmente o controle de endoparasitas. 
Os dados coletados foram tabulados e analisados em planilha eletrônica do Microsoft Excel. A análise estatística foi realizada no programa SPSS, consistindo da utilização do teste $t$ de Student para a comparação entre o desempenho dos dois grupos nos diferentes períodos. Os parâmetros utilizados para análise biológica no $1^{\circ} \mathrm{P}$ foram: peso médio inicial (PMI-1); peso médio final (PMF-1); ganho de peso médio diário (GMD-1); e tempo médio de permanência (TMP-1). No $2^{\circ} \mathrm{P}$ foram analisados: peso médio inicial (PMI-2); peso médio ao abate (PMA); e tempo médio de permanência (TMP-2). No período total $\left(1^{\circ} \mathrm{P}+2^{\circ} \mathrm{P}\right)$ foram analisados: peso médio inicial (PMI); peso médio ao abate (PMA); ganho de peso médio diário (GMD-T); tempo médio de permanência (TMP-T); e porcentagem de ganho de peso (\%GP). Para análise econômica foram utilizados os seguintes parâmetros: custo total/ animal; custo de aquisição/animal; custo de aquisição/ $\mathrm{kg}$; custo de alimentação/animal; custo de produção/kg produzido; custo total $/ \mathrm{kg}$ comercializado; receita bruta/ animal; receita bruta/kg; margem bruta/animal; lucratividade no período; lucratividade/mês; e diferença de preço compra/venda. Para o cálculo de custo total/ animal foi considerado o custo de aquisição dos animais acrescido do custo de alimentação. Os demais custos (mão-de-obra, medicamentos, depreciação) não foram computados pelo fato de estarem diluídos nas demais atividades da propriedade e representarem um valor pouco significativo [14,18]. No custo de alimentação/animal foram computados dados referentes ao custo do concentrado e ao custo da cobertura de nitrogênio realizada na pastagem de azevém, distribuídos para cada animal conforme quantidade de concentrado consumido e tempo de permanência no azevém. As receitas foram obtidas a partir do valor de venda dos animais. A margem bruta foi calculada a partir da diferença entre a receita e o custo total. A lucratividade no período foi calculada pela divisão da margem bruta pelo custo total. A lucratividade ao mês foi calculada pela divisão da lucratividade no período por 30 dias. $\mathrm{O}$ custo de produção/kg produzido foi calculado pela razão entre o custo da alimentação e o total de kg produzidos durante o período. $\mathrm{O}$ custo total $/ \mathrm{kg}$ comercializado foi calculado pela razão entre o custo total do processo e o total de $\mathrm{kg}$ comercializados.

\section{RESULTADOS}

Os valores obtidos para peso médio inicial (PMI-1), peso médio final (PMF-1), ganho de peso médio diário (GMD-1) e tempo médio de permanência (TMP-1) no $1^{\circ}$ período são apresentados na Tabela 1. O PMI-1 não apresentou diferença estatística significativa. O PMF-1 e o GMD-1 foram maiores $(\mathrm{p}<0,01)$ para $18 \mathrm{M}$ em relação à $18 \mathrm{~F}$. O TMP-1 foi o mesmo para ambos os grupos ( $>0,05)$.

Na Tabela 2 podem ser visualizados os dados obtidos para peso médio ao início do $2^{\circ}$ período (PMI2), peso médio ao abate (PMA), ganho de peso médio diário no $2^{\circ}$ período (GMD-2) e tempo médio de permanência no $2^{\circ}$ período (TMP-2). O PMI-2, o PMA e o GMD-2 foram maiores $(p<0,01)$ para os machos em relação às fêmeas. O TMP-2 foi não apresentou diferença significativa entre os grupos analisados $(p>0,05)$.

Na tabela 3 são mostrados os resultados obtidos para o período total $\left(1^{\circ} \mathrm{P}+2^{\circ} \mathrm{P}\right)$. O PMI e o PMA correspondem aos resultados dos períodos 1 e 2 , e já foram mostrados anteriormente. O GMD-T foi maior $(\mathrm{p}<0,01)$ para machos em relação a fêmeas, e resulta dos GMDs obtidos nos períodos 1 e 2. O TMP-T foi semelhante para $18 \mathrm{M}$ e $18 \mathrm{~F}(\mathrm{p}>0,05)$. A \%GP foi maior $(p<0,01)$ para os machos em relação às fêmeas.

Confrontando os resultados obtidos nos dois períodos de tratamento (Tabela 4), observam-se maiores $(\mathrm{p}<0,01)$ taxas de ganho de peso no $2^{\circ} \mathrm{P}$ em comparação com os resultados do $1^{\circ} \mathrm{P}$, tanto para $18 \mathrm{M}$ quanto para $18 \mathrm{~F}$.

\begin{tabular}{|c|c|c|c|c|}
\hline Grupo & PMI-1 (kg) & PMF-1 (kg) & GMD-1 (kg/dia) & TMP-1 (dias) \\
\hline $18 \mathrm{M}$ & $282,62 \pm 19,00$ & $312,86^{a} \pm 19,47$ & $0,550^{a} \pm 0,149$ & $55 \pm 0,000$ \\
\hline $18 \mathrm{~F}$ & $278,19 \pm 19,81$ & $295,77^{b} \pm 22,79$ & $0,320^{b} \pm 0,167$ & $55 \pm 0,000$ \\
\hline Média & $280,17 \pm 19,37$ & $303,40 \pm 22,82$ & $0,422 \pm 0,195$ & $55 \pm 0,000$ \\
\hline
\end{tabular}


Tabela 2. Peso Médio Inicial (PMI-2), Peso Médio ao Abate (PMA), Ganho de Peso Médio Diário (GMD-2) e Tempo Médio de Permanência (TMP-2), obtidos pelos grupos $18 \mathrm{M}$ e $18 \mathrm{~F}$ durante o $2^{\circ}$ Período (de 22/7 a 26/10/2005), com os respectivos desvios-padrão.

\begin{tabular}{ccccc}
\hline Grupo & PMI-2 $(\mathbf{k g})$ & PMA $(\mathbf{k g})$ & GMD-2 $(\mathbf{k g} /$ dia) & TMP-2 (dias) \\
\hline $18 \mathrm{M}$ & $312,86^{\mathrm{a}} \pm 19,47$ & $411,48^{\mathrm{a}} \pm 27,12$ & $1,302^{\mathrm{a}} \pm 0,218$ & $76,62 \pm 16,624$ \\
$18 \mathrm{~F}$ & $295,77^{\mathrm{b}} \pm 22,79$ & $371,92^{\mathrm{b}} \pm 23,98$ & $1,022^{\mathrm{b}} \pm 0,152$ & $74,00 \pm 15,852$ \\
Média & $303,40 \pm 22,82$ & $389,61 \pm 32,05$ & $1,147 \pm 0,230$ & $75,17 \pm 16,076$ \\
\hline \multicolumn{4}{c}{ a,b Médias na mesma coluna, seguidas de letras diferentes diferem entre $\mathrm{si}(\mathrm{p}<0,01)}$.
\end{tabular}

Tabela 3. Peso Médio Inicial (PMI-1), Peso Médio ao Abate (PMA), Ganho de Peso Médio Diário (GMD-T) e Tempo Médio de Permanência (TMP-T), obtidos pelos grupos 18M e 18F durante o Período Total (de 27/5 a 26/10/2005), com os respectivos desvios-padrão.

\begin{tabular}{cccccc}
\hline Grupo & PMI $(\mathbf{k g})$ & PMA $(\mathbf{k g})$ & GMD-T (kg/dia) & TMP-T (dias) & \%GP (\%) \\
\hline $18 \mathrm{M}$ & $282,62 \pm 19,00$ & $411,48^{\mathrm{a}} \pm 27,12$ & $0,979^{\mathrm{a}} \pm 0,139$ & $131,6 \pm 16,624$ & $45,94^{\mathrm{a}} \pm 10,06$ \\
$18 \mathrm{~F}$ & $278,19 \pm 19,81$ & $371,92^{\mathrm{b}} \pm 23,98$ & $0,724^{\mathrm{b}} \pm 0,099$ & $129,0 \pm 15,852$ & $34,01^{\mathrm{b}} \pm 8,32$ \\
Média & $280,17 \pm 19,37$ & $389,61 \pm 32,05$ & $0,838 \pm 0,173$ & $130,17 \pm 16,076$ & $39,34 \pm 10,84$ \\
\hline \multicolumn{7}{c}{ a,b Médias na mesma coluna, seguidas de letras diferentes diferem entre si $(\mathrm{p}<0,01)}$.
\end{tabular}

Tabela 4. Comparação entre o Ganho de Peso Médio Diário no $1^{\circ}$ Período (GMD-1) e no $2^{\circ}$ Período (GMD-2), em kg/dia, obtidos pelos grupos $18 \mathrm{M}$ e $18 \mathrm{~F}$ durante o processo de suplementação (com os respectivos desviospadrão).

\begin{tabular}{cccc}
\hline Período & $18 \mathrm{M}$ & $\mathbf{1 8 F}$ & Média \\
\hline $1^{\circ}$ Período & $0,55^{\mathrm{aA}} \pm 0,15$ & $0,32^{\mathrm{aB}} \pm 0,17$ & $0,423^{\mathrm{A}} \pm 0,16$ \\
$2^{\circ}$ Período & $1,30^{\mathrm{bA}} \pm 0,22$ & $1,02^{\mathrm{bB}} \pm 0,15$ & $1,147^{\mathrm{B}} \pm 0,23$ \\
\hline a,b Médias na mesma coluna, seguidas de letras diferentes diferem entre $\mathrm{si}(\mathrm{p}<0,01) .{ }^{\mathrm{A}, \mathrm{B}}$ Médias \\
na mesma linha, seguidas de letras diferentes diferem entre si $(\mathrm{p}<0,01)$.
\end{tabular}

Na Tabela 5 podem ser visualizados dados referentes à análise econômica do processo de suplementação, baseada nos custos de produção bem como nas receitas obtidas com a venda dos animais. $\mathrm{O}$ custo de aquisição/ $\mathrm{kg}$ foi maior $(\mathrm{p}<0,01)$ para $18 \mathrm{M}$ do que para $18 \mathrm{~F}$, resultando em um maior $(\mathrm{p}<0,01)$ custo de aquisição/animal para machos em relação a fêmeas. O custo de alimentação/animal foi semelhante $(\mathrm{p}>0,05)$ para os dois grupos. O custo de produção/kg produzido foi maior $(\mathrm{p}<0,01)$ para fêmeas em relação a machos. O custo total $/ \mathrm{kg}$ comercializado não apresentou variação significativa entre os grupos analisados ( $>0,05$ ). As variáveis receita bruta $/ \mathrm{kg}$, receita bruta/ animal, margem bruta/animal, lucratividade no período e lucratividade/mês foram superiores $(\mathrm{p}<0,01)$ para machos em relação à fêmeas. A diferença de preço compra/venda também foi semelhante para os dois grupos $(\mathrm{p}>0,05)$.

\section{DISCUSSÃO}

Machos foram mais pesados $(\mathrm{p}<0,01)$ ao final do $1^{\circ} \mathrm{P}$ devido ao maior $(\mathrm{p}<0,01)$ GMD-1 obtido por esses animais em relação às fêmeas. Machos ganham de 8 a $15 \%$ a mais de peso do que fêmeas da mesma idade [13]. No presente trabalho os machos ganharam, no $1^{\circ} \mathrm{P}$, em média $71,9 \%$ a mais de peso do que as fêmeas, sendo a superioridade dos mesmos maior do que a relatada no trabalho citado. Por outro lado [14], suplementando em campo nativo no outono machos e fêmeas para abate aos 18 meses, obtiveram GMD de $0,540 \mathrm{~kg} / \mathrm{dia}$, não apresentando diferenças estatísticas entre os sexos. Trabalhando com novilhos de 20 meses 


\begin{tabular}{|c|c|c|c|}
\hline & $18 \mathrm{M}$ & $18 \mathrm{~F}$ & Média \\
\hline Número de animais & 21 & 26 & 47 \\
\hline Custo total/animal & $580,56^{a} \pm 38,196$ & $528,13^{b} \pm 29,284$ & $551,55 \pm 42,362$ \\
\hline Custo de aquisição/animal & $438,06^{a} \pm 29,448$ & $389,47^{b} \pm 27,730$ & $411,18 \pm 37,299$ \\
\hline Custo de aquisição/kg & $1,55^{\mathrm{a}}$ & $1,40^{\mathrm{b}}$ & $1,47 \pm 0,000$ \\
\hline Custo alimentação/animal & $142,50 \pm 24,354$ & $138,66 \pm 23,223$ & $140,37 \pm 23,552$ \\
\hline Custo de produção/kg produzido & $1,12^{\mathrm{a}} \pm 0,178$ & $1,50^{\mathrm{b}} \quad 0,202$ & $1,33 \pm 0,269$ \\
\hline Custo total/kg comercializado & $1,41 \pm 0,067$ & $1,42 \pm 0,048$ & $1,42 \pm 0,057$ \\
\hline Receita bruta/animal & $699,51^{a} \pm 46,103$ & $567,95^{\mathrm{b}} \pm 44,442$ & $626,73 \pm 79,805$ \\
\hline Receita bruta/kg & $1,70^{\mathrm{a}} \pm 0,000$ & $1,53^{b} \pm 0,050$ & $1,61 \pm 0,094$ \\
\hline Margem bruta/animal & $118,95^{a} \pm 31,665$ & $39,82^{b} \pm 29,601$ & $75,18 \pm 49,938$ \\
\hline Lucratividade/período (\%) & $20,63^{a} \pm 5,87$ & $7,52^{b} \pm 5,63$ & $13,38 \pm 8,694$ \\
\hline Lucratividade/mês (\%) & $4,79^{\mathrm{a}} \pm 1,48$ & $1,88^{b} \pm 1,45$ & $3,18 \pm 2,06$ \\
\hline Diferença preço compra/venda (\%) & $9,68 \pm 0,00$ & $9,20 \pm 3,60$ & $9,42 \pm 2,66$ \\
\hline
\end{tabular}

em suplementação, [9] obtiveram GMDs entre 0,460 e $0,570 \mathrm{~kg} / \mathrm{dia}$. Em outro experimento [37], onde foi utilizado suplemento semelhante ao deste trabalho, fornecido a $0,8 \%$ do peso vivo na época da seca, o autor relata GMD similar, de aproximadamente $0,500 \mathrm{~kg} / \mathrm{dia}$.

O PMI-2 foi resultado do desempenho dos animais no $1^{\circ} \mathrm{P}$, indicando que o maior GMD-1 apresentado pelos machos resultou em um maior peso para esses animais ao início do $2^{\circ} \mathrm{P}$. O menor PMA obtido pelas fêmeas indica que essas alcançam o grau de acabamento de gordura necessário para o abate com um peso menor do que machos da mesma idade e tamanho. Trabalhos de pesquisa [8,11] explicam essa situação, afirmando que novilhas a um menor peso têm mais gordura corporal tanto em quantidade quanto em porcentagem, alcançando antes o peso de terminação. Além disso, quando os animais são alimentados para um constante grau de acabamento, ou seja, a uma mesma composição de carcaça, novilhas vão pesar aproximadamente $80 \%$ do peso de novilhos do mesmo tipo e tamanho [11]. No presente trabalho as fêmeas atingiram, ao abate, cerca de $90 \%$ do peso dos machos, corroborando com essa afirmação. Com isso, a terminação de fêmeas jovens torna-se uma opção vantajosa em situações onde é necessário antecipar o abate dos animais, sem, no entanto, deixar de obter carcaças bem acabadas.
O GMD-2 corroborou com os resultados obtidos no $1^{\circ} \mathrm{P}$, que indicaram maior potencial biológico para machos. Fêmeas apresentam menor eficiência de engorda do que machos, isto é, para um mesmo ganho médio diário, demandam uma maior densidade energética da dieta [18]. Por isso, quando submetidos ao mesmo regime alimentar, machos apresentam um melhor desempenho biológico. Contudo, cabe ressaltar que ambos os grupos apresentaram, no $2^{\circ} \mathrm{P}$, taxas de ganho de peso adequadas, visto que a dieta foi ajustada para GMD de 1,0 kg/dia. Os resultados alcançados para as fêmeas são semelhantes aos relatados por [27], que obtiveram GMD de 1,0 kg/dia suplementando com grão de sorgo novilhas em pastagem de inverno com alta disponibilidade de forragem. Resultados superiores foram relatados por [7], que suplementando novilhos em pastagem cultivada de inverno com grão de milho, verificaram GMD superior a 1,5 kg/dia.

O TMP-2, semelhante para os dois grupos, pode ser atribuído ao menor peso de abate atingido pelas fêmeas, o que permitiu que essas permanecessem por um período de tempo semelhante aos machos. Isso indica que mesmo tendo menor potencial para ganho de peso, fêmeas podem ser terminadas em um espaço de tempo semelhante aos machos, devido a sua maior facilidade de acabamento, como já discutido anterior- 
mente. O PMI e o PMA correspondem aos resultados dos períodos 1 e 2 , e já foram relatados anteriormente.

A maior \%GP obtida pelos machos em relação às fêmeas indica que esses necessitam ganhar mais peso para atingirem o grau de acabamento adequado, por apresentarem um maior peso ao abate. Contudo, cabe ressaltar que a variação de desempenho animal quando adotada a suplementação em pastejo é elevada. Desta forma, diferenças registradas entre os trabalhos de pesquisa podem estar ligadas aos parâmetros relacionados às interações forragem - suplemento animal, as quais são caracterizadas individualmente a cada experimento [1].

Ambos os grupos apresentaram maior GMD-2 em relação ao GMD-1, indicando que o aumento da quantidade de suplemento fornecida (de $0,6 \%$ para $0,8 \% \mathrm{PV}$ ) e a introdução da pastagem de azevém à dieta, parecem ter proporcionado um melhor desempenho biológico no $2^{\circ} \mathrm{P}$. Apesar das pastagens utilizadas no experimento não terem sido analisadas bromatologicamente, trabalhos de pesquisa $[6,28,33]$ reportam maiores teores de proteína bruta e energia, além de maior digestibilidade da pastagem de azevém, quando comparada às pastagens nativas do Rio Grande do Sul. Portando, o maior GMD obtido pelos animais no $2^{\circ} \mathrm{P}$ pode ser atribuído ao maior aporte nutricional oferecido aos animais nesse período.

$\mathrm{O}$ maior custo de aquisição/kg verificado para o grupo 18M indica uma característica de mercado, onde fêmeas de reposição normalmente são adquiridas por um preço menor em relação aos machos da mesma idade. Isso resultou em um maior custo de aquisição/animal para machos em relação a fêmeas, visto que os animais de ambos os grupos foram comprados com pesos semelhantes. Esse custo representou, em relação ao custo total, respectivamente para machos e fêmeas, 73,46 e 73,74\%, indicando que a aquisição dos animais foi a fração mais onerosa dentre os custos produção computados. Esses resultados ressaltam a importância da aquisição dos animais nesse tipo de processo, pois uma pequena economia na compra dos animais gera redução considerável do custo total [20].

O custo de alimentação/animal está relacionado ao TMP. Este, por sua vez, foi semelhante para os dois grupos, não havendo, portanto, diferença estatística entre os dois grupos nessa variável. A alimentação representou, respectivamente para machos e fêmeas, 24,54 e $26,26 \%$ do custo total, exercendo influência direta sobre o retorno econômico do processo. Segundo [17], o sucesso no manejo do gado de corte depende do conhecimento dos requerimentos nutricionais dos animais e da compreensão dos processos e funções que os compõe. Com isso, o conhecimento do valor nutricional dos alimentos a serem empregados, bem como a maximização da utilização dos mesmos através de animais mais eficientes tornam-se fundamentais.

$\mathrm{O}$ menor custo de produção/kg produzido observado para o grupo $18 \mathrm{M}$, refere-se ao custo da alimentação, e pode ser explicado pelo maior número de $\mathrm{kg}$ produzidos pelos machos durante o experimento, gerando uma maior porcentagem de ganho de peso, obtendo assim um menor custo de produção/kg produzido em relação às fêmeas, visto que o custo da alimentação/animal foi semelhante para os dois grupos. Resultado semelhante foi encontrado por [24], que terminando novilhos aos 15 e 22 meses de idade, obtiveram um custo/kg de ganho de peso de $\mathrm{R} \$ 1,29$ em média. Com esses resultados, fica claro que a utilização de animais mais eficientes reduz consideravelmente os custos de produção em processos de terminação de bovinos de corte.

O custo total $/ \mathrm{kg}$ comercializado não apresentou variação significativa. Apesar do custo total ter sido maior para os machos, os mesmos ganharam mais peso durante o experimento, permitindo assim um custo/kg comercializado semelhante às fêmeas.

A receita bruta $/ \mathrm{kg}$, maior para machos em relação a fêmeas, indica uma característica de mercado, com melhor remuneração para os machos a exemplo do que ocorreu na compra dos animais. A receita bruta/ animal, por sua vez, também foi superior para os machos, pois além de terem obtido uma melhor remuneração/kg, foram vendidos com maior peso corporal, gerando assim uma maior receita bruta. Em trabalho de pesquisa realizado na mesma área experimental, os autores reportam resultados semelhantes, com maior receita bruta/kg e receita bruta/animal para machos $(\mathrm{R} \$ 1,77$ e $\mathrm{R} \$ 670,83)$ em relação a fêmeas $(\mathrm{R} \$ 1,68$ e $R \$ 625,61$, respectivamente) [14].

A margem bruta/animal, a lucratividade no período e a lucratividade/mês, maiores para os machos, indicam que os esses foram mais eficientes do que as fêmeas do ponto de vista econômico. Esses resultados ressaltam a influência exercida pelo desempenho biológico dos animais suplementados sobre o retorno econômico obtido. Ou seja, o maior ganho de peso e o maior peso ao abate expressos pelos machos du- 
rante o experimento auxiliaram na obtenção de um retorno econômico superior para esses animais.

A diferença entre preço de compra/venda é a variável que mede o retorno obtido com a alteração no preço do $\mathrm{kg}$ gordo em relação ao $\mathrm{kg}$ magro [24]. Essa diferença foi semelhante $(\mathrm{p}>0,05)$ para os dois grupos, e exerceu influência direta sobre o resultado econômico tanto para machos quanto para fêmeas, pois além do valor recebido pelo número de quilogramas de ganho de peso durante a suplementação, existe um valor agregado ao $\mathrm{kg}$ de peso inicial (magro) em relação ao $\mathrm{kg}$ vendido.

\section{CONCLUSÕES}

Machos obtiveram maior eficiência biológica e econômica do que fêmeas. $\mathrm{O}$ ganho de peso médio diário obtido na suplementação de machos e fêmeas foi superior em pastagem cultivada quando comparado ao campo nativo. Fêmeas apresentaram menor ganho de peso médio diário e peso ao abate em relação aos machos, sem diferir o tempo médio de permanência. A terminação de machos e fêmeas para abate aos 18 meses através do uso de suplementação alimentar em campo nativo e pastagem cultivada mostrou-se viável economicamente.

\section{REFERÊNCIAS}

1 Alberto E. 1997. Effectos de la calidad de los forrajes y la suplementacion en el desempeño de ruminantes em pastoreo (com especial referencia a vacas lecheras). In: Anais do Simpósio Sobre Avaliação de Pastagens com Animais (Maringá, Brasil). pp.53-73.

2 Bertol I., Gomes K.E., Denardin R.B.N., Machado L.A.Z. \& Maraschin G.E. 1998. Propriedades físicas do solo relacionadas a diferentes níveis de oferta de forragem numa pastagem natural. Pesquisa Agropecuária Brasileira. 33: 779-786.

3 Bodine T.N. \& Purvis H.T. 2003. Effects of supplemental energy and/or degradable intake protein on performance, grazing behavior, intake, digestibility, and fecal and blood indices by beef steers grazed on dormant native tallgrass prairie. Journal of Animal Science. 81: 304-317.

4 Brondani I.L., Alves Filho D.C., \& Bernardes R.A.C. 2000. Silagem de alta qualidade para bovinos. In: Restle J. (Ed.) Eficiência na produção de bovinos de corte. Santa Maria: UFSM. pp.185-204.

5 Brustolin K.D., Quadros F.L.F., Viégas J., Gabbi A.M., Carlotto S.B., Cardoso A.R., Fontoura P.G. \& Piuco M.A. 2005. Recria de bezerros em pastagem de aveia e azevém utilizando suplementação energética com níveis de promotor de crescimento. Ciência Rural. 35: 428-434.

6 Cachapuz J.M. 1997. Experiências com desmame aos 90 e 60 dias. 2a Ed. Porto Alegre: EMATER-RS, 52p.

7 Calça K.G., Ferreira M.V.B. \& Pascoal L.L. 1996. Suplementação de novilhos de sobreano mantidos em pastagem cultivada de inverno. In: Anais da Jornada integrada de pesquisa, extensão e ensino. (Santa Maria, Brasil). p. 547.

8 Di Marco O. N. 1998. Crecimiento de vacunos para carne. Mar Del Plata: Balcarce, 246p.

9 El-Memari Neto A.C., Zeoula L. M., Cecato U., Prado I.N., Caldas Neto S.F., Kazama R. \& Oliveira F.C.L. 2003. Suplementação de novilhos nelore em pastejo de Brachiaria brizantha com diferentes níveis e fontes de concentrado. Revista Brasileira de Zootecnia. 32 (Supl 2): 1945-1955.

10 Garcia J., Alcalde C.R., Zambom M., Jobim C.C., Andrade S.R. \& Pereira M.F. 2004. Desempenho de novilhos em crescimento em pastagem de Brachiaria decumbens suplementados com diferentes fontes energéticas no período da seca e transição seca-águas. Revista Brasileira Zootecnia. 33 (Supl 2): 2140-2150.

11 Gottschall C.S. 1999. Impacto nutricional na produção de carne - curva de crescimento. In: Lobato J.F.P., Barcellos J.O.J. \& Kessler A.M. (Eds.). Produção de bovinos de corte. Porto Alegre: PUCRS, pp.169-192.

12 Gottschall C. S. 2004. Bovinocultura de Corte: Planejamento técnico e gerencial da atividade. In: Anais do IX Ciclo de palestras em produção e manejo de bovinos. (Canoas, Brasil). pp. 7-34.

13 Gottschall C.S. 2005. Produção de novilhos precoces - Nutrição, manejo e custos de produção. $2^{\mathrm{a}}$ ed. Guaíba: Ed. Agropecuária, $213 p$.

14 Gottschall C.S., Canellas L.C., Ferreira E.T., Marques P.R., Sommer C., Lourenzen G. \& Bittencourt H.R. 2005. Desempenho de novilhos e novilhas de corte de diferentes idades terminados em regime de suplementação alimentar em pastagem cultivada e campo nativo. Veterinária em Foco. 3: 67-78.

15 Heck I., Brondani I.L., Menezes L.F.G., Alves Filho D.C., Restle J., Ferreira J.J., Metz P.A.M. \& Farenzena R. 2006. Suplementação com diferentes níveis de silagem de milho para vacas de descarte de diferentes grupos genéticos submetidas ao pastejo. Ciência Rural. 36: 203-208. 
16 Knorr M., Patiño H.O., Silveira A.L.F., Mühlbach P.R.F., Mallmann G.M. \& Medeiros F.S. 2005. Desempenho de novilhos suplementados com sais proteinados em pastagem nativa. Pesquisa Agropecuária Brasileira. 40: 783-788.

17 Lanna D.P., Fox D.G. \& Tedeschi L.O. 1998. Exigências nutricionais de gado de corte: o sistema NRC. In: Anais do Simpósio sobre produção intensiva de gado de corte (Campinas, Brasil). pp.138-167.

18 Lazzarini Neto S. 1994. Confinamento de bovinos de corte. São Paulo: SDF Editores, 96p.

19 Lima L.B. 2002. Suplementação protéico mineral de bovinos em pastejo. In: Anais do VII Ciclo de palestras em produção e manejo de bovinos (Canoas, Brasil). pp. 127-147.

20 Lopes M.A. \& Magalhães G.P. 2005. Rentabilidade na terminação de bovinos de corte em confinamento: Um estudo de caso em 2003, na região oeste de Minas Gerais. Ciênc. agrotec. 29: 1039-1044.

21 Nabinger C. 2002. Sistemas de pastoreio e alternativas de manejo de pastagens. In: Anais do VII Ciclo de palestras em produção e manejo de bovinos. (Canoas, Brasil). pp. 7-60.

22 National Research Council (NRC). 1996. Nutrient Requeriments of Beff Cattle. $7^{\text {th }}$ ed. Washington: National Academy Press, $246 \mathrm{p}$.

23 Ospina H.O. \& Medeiros F.S. 2003. Suplementação a pasto: uma alternativa para produção de novilho precoce. In: Anais do Simpósio internacional da carne bovina: da produção ao mercado consumidor. (São Borja, Brasil). pp.83-115.

24 Pacheco P.S., Restle J., Vaz F.N., Freitas A.K., Padua J.T., Neumann M. \& Arboitte M.Z. 2006. Avaliação econômica da terminação em confinamento de novilhos jovens e superjovens de diferentes grupos genéticos. Revista Brasileira de Zootecnia. 35: 309-320.

25 Pascoal L.L., Restle J. \& Roso C. 1999. Desempenho e economicidade da suplementação em pastagem. In: Restle J. (Ed.) Confinamento, pastagens e suplementação para produção de bovinos de corte. Santa Maria: UFSM. pp.62-84.

26 Paulino M.F., Detmann E., Valadares Filho S. C. \& Lana R.P. 2002. Soja Grão e Caroço de Algodão em Suplementos Múltiplos para Terminação de Bovinos Mestiços em Pastejo. Revista Brasileira de Zootecnia. 31 (Supl): 484-491.

27 Pilau A., Rocha M.G., Restle J., Freitas F.K. \& Roso D. 2005. Produção de forragem e produção animal em pastagem com duas disponibilidades de forragem associadas ou não à suplementação energética. Revista Brasileira de Zootecnia. 34: 1130-1137.

28 Quadros F.L.F. 1999. Produtividade animal a pasto: manejo e utilização de forrageiras de inverno em terras altas, integrando lavoura do seco e pecuária. In: Anais do IV Ciclo de palestras em produção e manejo de bovinos de corte: manejo e utilização sustentável de pastagens. (Canoas, Brasil). pp. 91-100.

29 Restle J. 1999. Confinamento, pastagens e suplementação para produção de bovinos de corte. Santa Maria: UFSM. 259p.

30 Restle J., Neumann M., Brondani I.L., Alves Filho D.C., Silva J.H.S., Gonçalves J.M. \& Kuss F. 2002. Produção do superprecoce a partir de bezerros desmamados aos 72 ou 210 dias de idade. Revista Brasileira Zootecnia. 31: 1803-1813.

31 Rocha M.G. 1999. Suplementação a campo de bovinos de corte. In: Lobato J.F.P., Barcellos J.O.J. \& Kessler A.M. (Eds.). Produção de bovinos de corte. Porto Alegre: PUCRS. pp.77-96.

32 Rocha M.G., Restle J., Pilau A. \& Santos D.T. 2003. Produção animal e retorno econômico da suplementação em pastagem de aveia e azevém. Ciência Rural. 33: 573-578.

33 Roso C., Restle J., Soares A.B. \& Andreatta E. 2000. Aveia preta, triticale e centeio em mistura com azevém. 1. Dinâmica, produção e qualidade de forragem. Revista Brasileira Zootecnia. 29: 75-84.

34 Rovira J. 1996. Manejo nutritivo de los rodeos de cria em pastoreo. Uruguay: Ed. Hemisfério Sur Montevideo, 288p.

35 Santos E.D.G., Paulino M.F., Valadares Filho S.C., Lana R.P., Queiroz D.S. \& Fonseca D.M. 2004. Terminação de tourinhos Limousin x Nelore em pastagem diferida de Brachiaria Decumbens stapf, durante a estação seca, alimentados com diferentes concentrados. Revista Brasileira de Zootecnia. 33: 1627-1637.

36 Santos D.T., Rocha M.G., \& Genro T.C. 2002. Produção animal em pastagem cultivada com ou sem o uso de suplementos energéticos para bezerras de corte. In: Anais da Reunião anual da sociedade brasileira de zootecnia (Recife, Brasil). 1 CD-ROM.

37 Thiago L.R. 1999. Suplementação de bovinos em pastejo - aspectos práticos para seu uso na mantença e ganho de peso. Disponível em: <http://www.cnpgc.embrapa.br/publicacoes/naoseriadas>. Acessado em 05/2006.

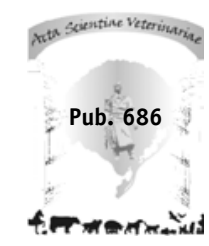

